\title{
Role of high-frequency USG in rotator cuff injury and its comparison with MRI
}

\author{
Maravi P. ${ }^{1 *}$, Khadiya A. ${ }^{2}$, Kaushal L. ${ }^{3}$, Goyal S. ${ }^{4}$, Patil P. ${ }^{5}$ \\ DOI: https://doi.org/10.17511/ijmrr.2020.i06.12 \\ 1* Poornima Maravi, Associate Professor, Department of Radiodiagnosis, Gandhi Medical College and Hamidia Hospital, Bhopal, Madhya \\ Pradesh, India. \\ 2 Ajay Khadiya, Junior Resident III, Gandhi Medical College and Hamidia Hospital, Bhopal, Madhya Prdaesh, India. \\ 3 Lovely Kaushal, Professor and HOD, Department of Radiodiagnosis, Gandhi Medical College and Hamidia Hospital, Bhopal, Madhya \\ Pradesh, India. \\ 4 Swati Goyal, Associate Professor, Department of Radiodiagnosis, Gandhi Medical College and Hamidia Hospital, Bhopal, Madhya Pradesh, \\ India. \\ 5 Pinki Patil, Assistant Professor, Department of Radiodiagnosis, Gandhi Medical College and Hamidia Hospital, Bhopal, Madhya Pradesh, \\ India.
}

Introduction: Rotator cuff injury is one of the common causes of long-term shoulder pain and disability encountered in the orthopedic clinic. The spectrum of rotator cuff injury includes tendonitis, partial tears, and complete tears. They also may influence the development of the degenerative disease of glenohumeral joint and rotator cuff arthropathy. Material and Methods: The present, prospective study entitled "Role of high-frequency USG in rotator cuff injury and its comparison with MRI" was conducted in the Department of Radiodiagnosis on a total of 100 patients who presented with signs and symptoms of shoulder joint injury in Department of Orthopedic who were then referred for USG and MRI examination to the Department of Radiodiagnosis. Result: Mean age of the patients was $38.26 \pm 14.51$ years and the majority of patients belonged to the $3^{\text {rd }}$ decade (34\%). About $7 \%$ of patients belonged to the $2^{\text {nd }}$ decade, $18 \%$ of patients each belonged to the $4^{\text {th }}$ and $5^{\text {th }}$ decades of age group. Only $8 \%$ and $7 \%$ of patients in the present study belonged to extremes of age i.e. $>60$ years and $<20$ years respectively. Conclusion: Based on the findings of the present study, it is concluded that rotator cuff injuries are commonly encountered conditions in routine practice, and males are commonly affected as compared to females.

Keywords: MRI, USG, Rotator cuff, Cuff injuries

Corresponding Author

Poornima Maravi, Associate Professor, Department of Radiodiagnosis, Gandhi Medical College and Hamidia Hospital, Bhopal, Madhya Pradesh, India.

Email: maravipoornima@gmail.com
How to Cite this Article

Maravi P, Khadiya A, Kaushal L, Goyal S, Patil P. Role of high-frequency USG in rotator cuff injury and its comparison with MRI. Int J Med Res Rev. 2020;8(6):440-450.

Available From

https://ijmrr.medresearch.in/index.php/ijmrr/article/ view/1237
To Browse

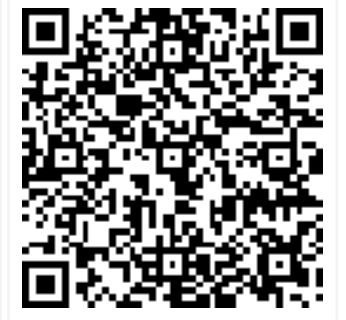

Manuscript Received 2020-12-18

Conflict of Interest No
Review Round 1 2020-12-25

Funding

Nil
Review Round 2 2020-12-28

Ethical Approval Yes
Review Round 3

Accepted 2020-12-31

Plagiarism X-checker $8 \%$

(c) 2020 by Poornima Maravi, Ajay Khadiya, Lovely Kaushal, Swati Goyal, Pinki Patil and Published by Siddharth Health Research and Social Welfare Society. This is an Open Access article licensed under a Creative Commons Attribution 4.0 International icense https://creativecommons.org/licenses/by/4.0/ unported [CC BY 4.0]. 


\section{Introduction}

The rotator cuff is comprised of four muscles that originate from the scapula and insert into the humerus. All these muscles collectively act to stabilize the shoulder joint [1].

Rotator cuff injury is one of the common causes of long-term shoulder pain and disability encountered in the orthopedic clinic [2]. The spectrum of rotator cuff injury includes tendonitis, partial tears, and complete tears. They also may influence the development of the degenerative disease of glenohumeral joint and rotator cuff arthropathy $[3,4]$.

Though rotator cuff injury is a clinical diagnosis, radiological imaging plays an important role particularly in identifying causal factors [5]. MRI is the gold standard technique for assessing the joint function and involvement of the tendon.

Rotator cuff tear is detected on MRI by the increased signal intensity with discontinuity or irregularity of tendon on $\mathrm{T} 2$ and proton density (PD)-weighted images. It is an excellent modality as it is non-invasive, gives superior soft-tissue resolution, and is a multiplanar approach [6].

Thus, MRI is an important modality for both the radiologist as well as the surgeon in planning the management approach [7]. MRI is contraindicated in patients with implants such as pacemakers, aneurysmal clips, cochlear implants [8].

Thus, there is a need for alternative imaging modality which have diagnostic accuracy equivalent to that of MRI. Accuracy of ultrasound to be comparable to MRI for diagnosis of rotator cuff tears [9-14].

\section{Materials and Methods}

The present, prospective study entitled "Role of high-frequency USG in rotator cuff injury and its comparison with MRI" was conducted in the Department of Radiodiagnosis on a total of 100 patients who presented with signs and symptoms of shoulder joint injury in the Department of Orthopedic who were then referred for USG and MRI examination to the Department of Radiodiagnosis.

Written consent: Written consent was obtained from all the study participants.
Methodology: After obtaining ethical clearance from the Institute's ethical committee, all the patients fulfilling the above-mentioned inclusion criteria were enrolled and written consent was obtained. Socio-demographic details were entered in the questionnaire. Further ultrasound and appropriate MRI sequences and multilane imaging were performed for every patient by the same examiner.

\section{USG}

The affected shoulder was examined on the USG machine available in our department, with a highfrequency linear transducer having a frequency range of 3-12 $\mathrm{MHz}$. The patients were sitting comfortably on a rotating stool in line of sight of monitoring with elbow was flexed at $90^{\circ}$ and arm rotated passively during the procedure. The rotator cuff tendons were examined in detail in 5 planes i.e. anterior, posterior, lateral, longitudinal, and transverse. First, Subscapularis and biceps tendons are evaluated followed by supraspinatus tendon and acromioclavicular joint with underlying bursa and then in last posterior structures like infraspinatus tendon, labrum, and teres minor were examined.

Step 1: Biceps brachia tendon, long head. The normal tendon will appear hyperechoic and fibrillar.

Step 2: Subscapularis and biceps tendon subluxation/dislocation.

Step 3: Supraspinatus and rotator interval.

Step 4: Acromioclavicular joint, subacromialsubdeltoid bursa, and dynamic evaluation for subacromial impingement.

Step 5: Infraspinatus, teres minor, and posterior labrum.

\section{MRI technique:}

Imaging was done with a 1.5 Tesla Hitachi machine using a shoulder coil. All scans were acquired in the supine position. The following sequences were used to obtain MRI images as required

01. Coronal oblique T1WI/ proton density (PD) W fast spin-echo (FSE) sequence.

02. Coronal oblique fat-suppressed (FS) Proton density (PD) W FSE / T2 W FSE sequence.

03. Sagittal oblique T2 W FSE sequence (with/without fat suppression).

04. Axial T2W gradient-echo (GE) sequence. 
05. Axial PDW fast spin-echo FSE (with/ without fat suppression)

Field of view as $14-16 \mathrm{~cm}$, slice thickness $2-3 \mathrm{~mm}$, and matrix $512 \times 512$.

\section{Statistical analysis}

Data was compiled using MS Excel and analyzed using IBM SPSS software version 20. Descriptive and inferential statistics were applied. Data were grouped, presented as frequency and percentage whereas numerical data were expressed as mean and standard deviation.

The proportions were compared using the chisquare test whereas the mean difference between the findings of MRI and USG were compared using the independent t-test. Diagnostic accuracy, sensitivity, specificity, NPV, and PPV for USG were calculated and expressed as a percentage.

Kappa statistics were applied to assess the level of agreement between the findings of MRI and USG. Pvalue $<0.05$ was considered significant.
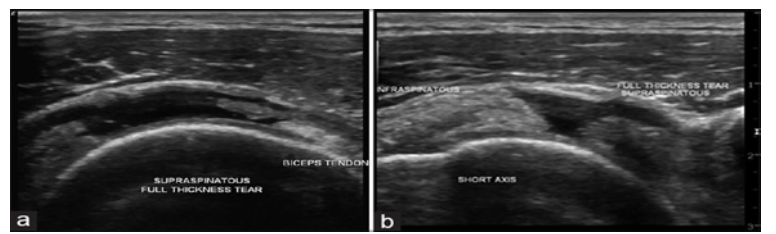

\section{Fig-1-USG depicting \\ supraspinatus tendon tear.}

Long- (a) and short-axis (b) examination reveals that there is a fluid-filled defect replacing the entire thickness and width of the right supraspinatus, suggesting a full-thickness tear of the supraspinatus tendon. The defect length of retraction is $30 \mathrm{~mm}$.

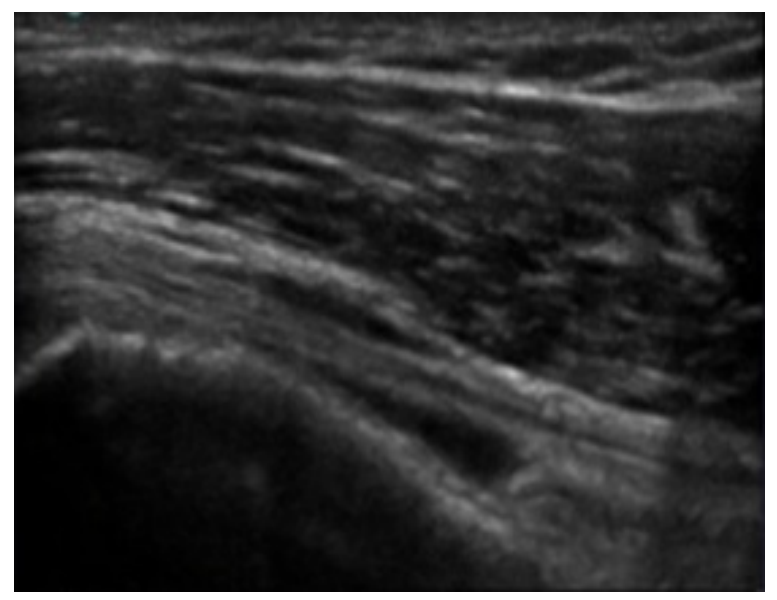

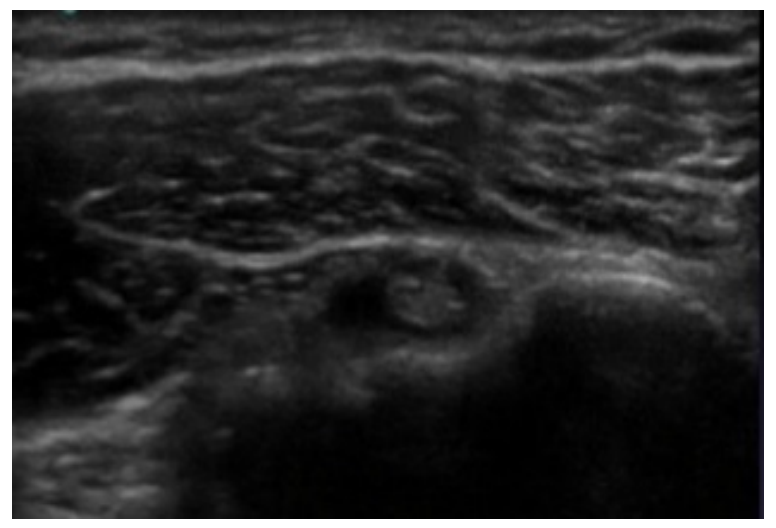

\section{Fig-2- Ultrasound image showing tendovaginitis of biceps tendon.}

Long- (a) and short-axis (b) examination of the long head of biceps brachii tendon reveals that it is hypoechoic, the fluid-filled area around the long biceps brachii tendon.

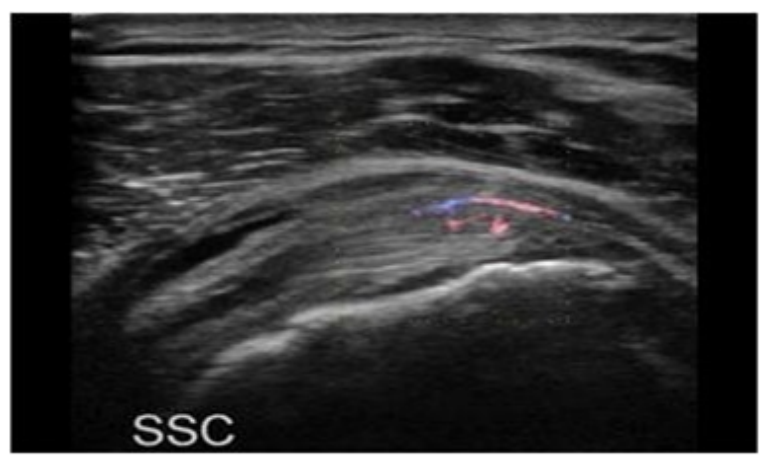

Fig-3- Ultrasound image showing tendinosis of subscapularis tendon.

Long axis examination of subscapularis tendon reveals that there is thickening with changes in normal contour, loss of normal fibrillar pattern, and hypoechoic changes on ultrasound with neovascularization within abnormal tendon on power Doppler examination.
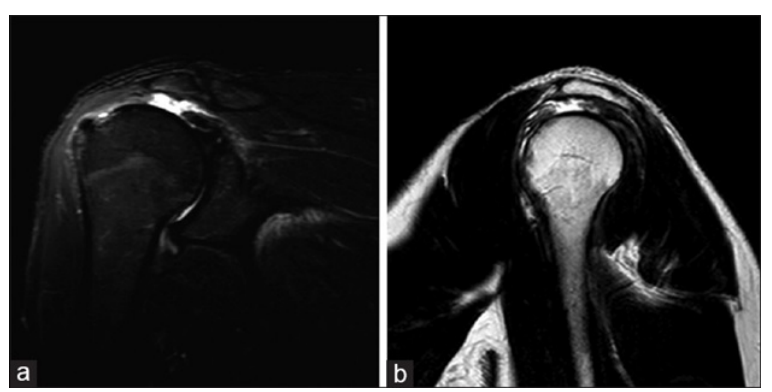

Fig-4: Coronal STIR image (a) and sagittal T2 image (b) showing a complete tear of the supraspinatus tendon, which is retracted 
Medially, uncovering the humeral head, with the subacromial bursal fluid collection.

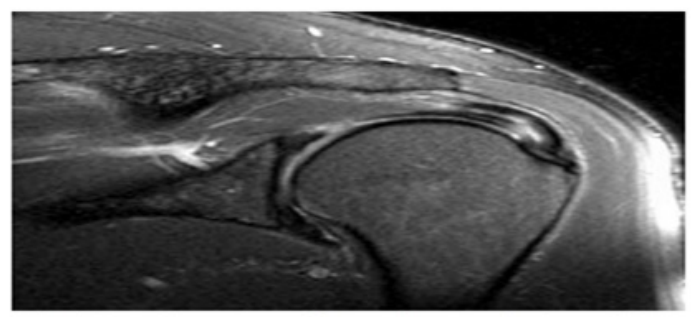

Intra substance tear of supraspinatus tendon

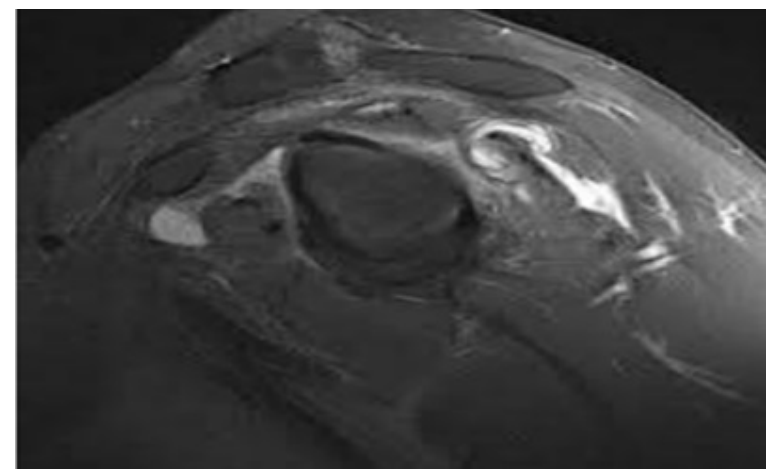

Infraspinatus tendon tear at myotendinous junction

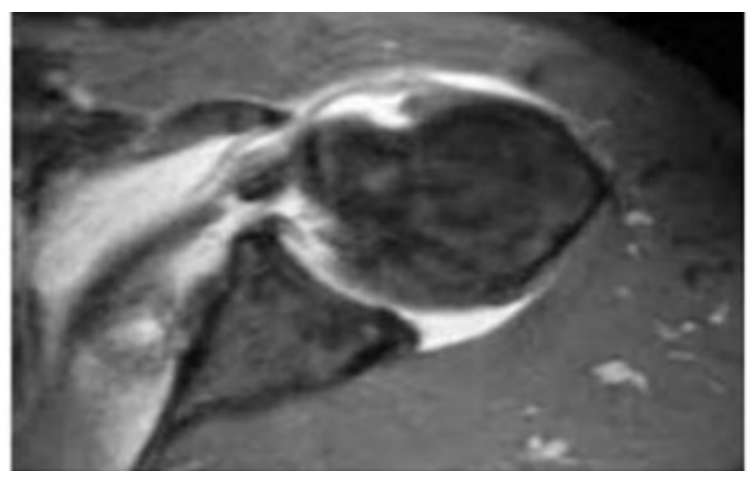

Partial thickness tear of subscapularis tendon

Fig-5: MRI images of partial and full-thickness tears.

\section{Results}

A total of 100 patients presenting with rotator cuff injuries during the study period were included. The findings of the present study are described as under:

Table-1: Distribution of rotator cuff injuries according to age group.

\begin{tabular}{|l|l|l|}
\hline \multicolumn{1}{|c|}{ Age } & \multicolumn{1}{c|}{ Frequency $(\mathrm{n}=\mathbf{1 0 0})$} & \multicolumn{1}{c|}{ Percentage $(\%)$} \\
\hline$\leq 20$ & 7 & 7.0 \\
\hline $21-30$ & 34 & 34.0 \\
\hline
\end{tabular}

\begin{tabular}{|l|l|l|}
\hline $31-40$ & 18 & 18.0 \\
\hline $41-50$ & 18 & 18.0 \\
\hline $51-60$ & 15 & 15.0 \\
\hline$>60$ & 8 & 8.0 \\
\hline
\end{tabular}

The mean age of the patients was $38.26 \pm 14.51$ years and the majority of patients belonged to the 3rd decade (34\%). About $7 \%$ of patients belonged to the 2nd decade, $18 \%$ of patients each belonged to the 4 th and 5 th decades of age group. Only $8 \%$ and $7 \%$ of patients in the present study belonged to extremes of age i.e. $>60$ years and $<20$ years respectively.

Table-2: Distribution of rotator cuff injuries according to gender.

\begin{tabular}{|l|l|l|}
\hline \multicolumn{1}{|c|}{ Gender } & \multicolumn{1}{|c|}{ Frequency $(\mathbf{n = 1 0 0 )}$} & \multicolumn{1}{c|}{ Percentage (\%) } \\
\hline Male & 74 & 74.0 \\
\hline Female & 26 & 26.0 \\
\hline
\end{tabular}

Male preponderance (74\%) was observed in the present study with a male: female ratio of $2.8: 1$. About $26 \%$ of the patients were females.

Table-3: Distribution of rotator cuff tears according to findings of USG

\begin{tabular}{|l|l|l|l|l|l|l|}
\hline \multirow{2}{*}{ Rotator cuff tear } & \multicolumn{3}{|c|}{ Frequency $(\mathbf{n = 1 0 0})$} & \multicolumn{3}{c|}{ Percentage (\%) } \\
\cline { 2 - 7 } & PTT & FTT & Total & PTT & FTT & Total \\
\hline Supraspinatus & 28 & 8 & 36 & $28 \%$ & $8 \%$ & $36 \%$ \\
\hline Infraspinatus & 2 & 0 & 2 & $2 \%$ & - & $2 \%$ \\
\hline Subscapularis & 9 & 1 & 10 & $9 \%$ & $1 \%$ & $10 \%$ \\
\hline Biceps & 4 & 0 & 4 & $4 \%$ & - & $4 \%$ \\
\hline *PTT-Partial Thickness Tear, * FTT- Full-Thickness Tear \\
\hline
\end{tabular}

On USG, supraspinatus tendon tears were the most common finding in $36 \%$ of patients (partial thickness tear-28\%; full-thickness tear-8\%) followed by subscapularis tendon tear in $10 \%$ (partial thickness tear- 9; full-thickness tear- 1\%), biceps tendon tear in 4\% (partial thickness tear) and infraspinatus tendon tear in $2 \%$ (partial thickness tear) cases.

Table-4: Distribution of rotator cuff injures according to the presence of effusion and bursitis on USG.

\begin{tabular}{|l|l|l|l|}
\hline \multicolumn{2}{|c|}{ USG } & Frequency $(\mathbf{n = 1 0 0})$ & Percentage (\%) \\
\hline Glenohuemral joint Effusion & 6 & $6 \%$ \\
\hline Biceps tendon sheath Effusion & 3 & $3 \%$ \\
\hline \multirow{3}{*}{ Bursitis } & Subacromial & 19 & $19 \%$ \\
\cline { 2 - 4 } & Subscapularis & 0 & - \\
\cline { 2 - 5 } & Subcoracoid & 0 & - \\
\hline
\end{tabular}

On USG glenohumeral joint effusion, subacromial bursitis and biceps tendon sheath effusion were observed in $6 \%, 19 \%$, and $3 \%$ cases respectively. 
Table-5: Distribution of rotator cuff tendon tears according to findings of MRI.

\begin{tabular}{|l|l|l|l|l|l|l|}
\hline \multirow{2}{*}{ Rotator cuff tear } & \multicolumn{3}{|c|}{ Frequency $(\mathbf{n = 1 0 0})$} & \multicolumn{3}{c|}{ Percentage (\%) } \\
\cline { 2 - 7 } & PTT & FTT & Total & PTT & FTT & Total \\
\hline Supraspinatus & 39 & 8 & 47 & $39 \%$ & $8 \%$ & $47 \%$ \\
\hline Infraspinatus & 2 & 0 & 2 & $2 \%$ & - & $2 \%$ \\
\hline Subscapularis & 12 & 1 & 13 & $12 \%$ & $1 \%$ & $13 \%$ \\
\hline Biceps & 3 & 0 & 3 & $3 \%$ & - & $3 \%$ \\
\hline *PTT- Partial Thickness Tear, * FTT- Full-Thickness Tear \\
\hline
\end{tabular}

In the present study, MRI revealed supraspinatus tendon tear in $47 \%$ cases (Partial thickness tear$39 \%$ Full-thickness tear-8\%) followed by subscapularis tendon tear in $13 \%$ cases (partial thickness tear -12\%; full-thickness tear in $1 \%$ case), biceps tendon tear in 3\% (Partial thickness tear) cases and infraspinatus tendon tears in $2 \%$ (Partial thickness tear) cases.

Table-6: Distribution of rotator cuff injuries according to the presence of effusion and bursitis in MRI.

\begin{tabular}{|l|l|l|l|}
\hline \multicolumn{1}{|c|}{ MRI } & Frequency $(\mathbf{n = 1 0 0})$ & Percentage (\%) \\
\hline Glenohuemral joint Effusion & 20 & $20 \%$ \\
\hline Biceps tendon sheath Effusion & 8 & $8 \%$ \\
\hline \multirow{4}{*}{ Bursitis } & Subacromial(subdeloid) & 23 & $23 \%$ \\
\cline { 2 - 4 } & Sub-coracoid & 3 & $3 \%$ \\
\cline { 2 - 4 } & Subscapularis & 0 & - \\
\cline { 2 - 4 } & Total & 26 & $26 \%$ \\
\hline
\end{tabular}

MRI revealed glenohumeral joint effusion and biceps tendon sheath effusion in $20 \%$ and $8 \%$ cases respectively whereas bursitis in $26 \%$ cases (subacromial bursitis in 23 cases; sub-coracoid bursitis in 3 cases) in the present study.

Table-7: (a)- Comparison of USG and MRI findings in rotator cuff tears.

\begin{tabular}{|l|l|l|l|}
\hline \multicolumn{1}{|c|}{ Tendon } & \multicolumn{1}{|c|}{ Type of tear } & \multicolumn{1}{c|}{ USG } & \multicolumn{1}{c|}{ MRI } \\
\hline \multirow{5}{*}{ Supraspinatus } & Partial Thickness Tear & 28 & 39 \\
\cline { 2 - 5 } & Full-Thickness Tear & 8 & 8 \\
\cline { 2 - 5 } & Total & 36 & 47 \\
\hline \multirow{5}{*}{ Infraspinatus } & Partial Thickness Tear & 2 & 2 \\
\cline { 2 - 5 } & Full-Thickness Tear & 0 & 0 \\
\cline { 2 - 5 } & Total & 2 & 2 \\
\hline \multirow{5}{*}{ Bubscapularis } & Partial Thickness Tear & 9 & 12 \\
\cline { 2 - 5 } & Full-Thickness Tear & 1 & 1 \\
\cline { 2 - 5 } & Total & 10 & 13 \\
\hline & Partial Thickness Tear & 4 & 3 \\
\cline { 2 - 5 } & Full-Thickness Tear & 0 & 0 \\
\cline { 2 - 4 } & Total & 4 & 3 \\
\hline
\end{tabular}

MRI revealed supraspinatus tendon tear in 47 patients, subscapularis tendon tear in 13 patients, infraspinatus tendon tear in 2 patients, and biceps tendon tear in 3 patients.

Out of 36 supraspinatus tendon tears on USG, 8 patients showed full-thickness tears and 28 patients showed partial-thickness tears. Out of these 28 patients with a partial-thickness tear in USG, 2 patients were found normal in MRI (false positive).

Thirteen patients which were found normal in USG (false negative), were detected as partial thickness tear in subsequent MRI. USG detected 34 true positive supraspinatus tears ( 8 full-thickness tears and 26 partial-thickness tears), 2 false-positive partial-thickness tears, and 13 false-negative as normal while 51 patients were diagnosed as normal (true negative).

Out of 10 subscapularis tendon tears on USG, 1 patient showed a full-thickness tear and 9 patients showed partial-thickness tears. Out of these 9 patients having partial-thickness tears, 1 patient was found normal in MRI (false positive). Ultrasound showed true positive tears ( 8 partial thickness tears and 1 full-thickness tear) in 9 patients. Four patients, who were found normal in USG, were diagnosed as having partial thickness tear in MRI (false negative).

USG detected 9 true positive subscapularis tears, 1 false-positive subscapularis partial thickness tear, and 4 false-negative subscapularis tendon tears as normal while 86 patients were diagnosed as normal subscapularis tendon (true negative).

USG detected 2 partial-thickness infraspinatus tendon tears. One patient showed a tear in MRI (true positive) and 1 patient was diagnosed as normal in MRI (false positive). MRI also showed partial thickness tear of infraspinatus tendon in 1 patient, which was falsely diagnosed as normal (false negative) on USG.

USG detected 1 true positive partial-thickness infraspinatus tear, 1 false-positive partial thickness tear, and 1 false-negative partial thickness tear while 97 patients were diagnosed as normal (true negative).

USG revealed 4 partial-thickness biceps tendon tears. Two patients showed partial-thickness tears in MRI (true positive) while 2 patients were found normal in MRI (false positive). One patient showed partial thickness tear in MRI, was falsely diagnosed as normal on USG (false negative). 
Thus, USG detected 2 true positive partial-thickness biceps tendon tears, 2 false-positive partialthickness tears, and 1 false-negative as normal while 95 patients were diagnosed as normal biceps tendon (true negative).

USG revealed supraspinatus tendon tear in 36 cases and infraspinatus tendon tear in 2 cases. Subsequent MRI examination revealed supraspinatus tear and infraspinatus tear in 47 cases and 2 cases respectively. Similarly, USG detected subscapularis tear in 10 cases while in MRI, subscapularis tendon tear was detected in 13 cases.

USG revealed biceps tendon tear in 4 cases while on MRI, biceps tendon tear was detected in 3 cases. In the present study, MRI finding was considered the gold standard, and based on its findings the diagnostic accuracy of ultrasound was individually calculated for respective muscle tears.

Table-7: (b)- Diagnostic accuracy of USG for musculotendinous injuries.

\begin{tabular}{|l|l|l|l|l|}
\hline & Supraspinatus & Infraspinatus & Subscapularis & Biceps \\
\hline Sensitivity & 72.3 & 50 & 69.2 & 66.6 \\
\hline Specificity & 96.3 & 98.9 & 98.8 & 97.9 \\
\hline PPV & 94.4 & 50 & 90 & 50 \\
\hline NPV & 80.3 & 98.9 & 95.6 & 98.9 \\
\hline Kappa (sig) & $0.735(0.001)$ & $0.66(0.001)$ & $0.79(0.001)$ & $0.80(0.001)$ \\
\hline
\end{tabular}

Based on table 7.a, the diagnostic accuracy of USG was calculated.

Overall, the sensitivity of USG was maximum for supraspinatus $(72.3 \%)$, followed by subscapularis, biceps, and infraspinatus tendon i.e. $69.2 \%, 66.6 \%$, and $50 \%$ respectively.

The negative predictive value of USG was maximum for both infraspinatus and biceps tendon tears i.e. $98.9 \%$ each respectively followed by subscapularis and supraspinatus tendon tear i.e. $95.6 \%$ and $80.3 \%$.

The specificity of USG was maximum for infraspinatus (98.9\%), followed by subscapularis, biceps, and supraspinatus tendon i.e. $98.8 \%$, $97.9 \%$, and $96.3 \%$ respectively.

Positive predictive value of USG was maximum for supraspinatus $(94.4 \%)$ followed by subscapularis $(90 \%)$ while the same for both infraspinatus and biceps tendon tear i.e. 50\% each respectively. Kappa statistics were applied to assess the level of agreement between MRI and USG in the findings of muscular tear.
A strong level of agreement (0.80) was observed between USG and MRI for the identification of biceps injuries. However, a moderate level of agreement was observed (0.60-0.79) for the other three (supraspinatus: 0.735 , subscapularis: 0.79 , infraspinatus: 0.66 ) rotator cuff injuries.

Table 8. (a)- Comparison of MRI and USG finding for presence of effusion and bursitis

\begin{tabular}{|l|l|l|}
\hline \multicolumn{1}{|c|}{ Findings } & USG & \multicolumn{1}{c|}{ MRI } \\
\hline Glenohumeral joint effusion & 6 & 20 \\
\hline Biceps tendon sheath effusion & 3 & 8 \\
\hline Subacromial bursitis & 19 & 23 \\
\hline Subscapularis bursitis & 0 & 0 \\
\hline Subcoracoid bursitis & 0 & 3 \\
\hline Total bursitis & 19 & 26 \\
\hline
\end{tabular}

In the present study, USG showed glenohumeral joint effusion in 6 cases while a similar finding was detected in 20 cases in MRI. Similarly, USG showed biceps tendon effusion and bursitis in 3 and 19 cases (including subacromial bursitis in 19 cases and subcoracoid / subscapularis bursitis in none of the cases) respectively. In MRI, biceps tendon sheath effusion and bursitis were diagnosed in 8 and 26 cases (including subacromial bursitis in 23 cases and subcoracoid bursitis in 3 cases) respectively.

Table 8. b- Diagnostic accuracy of USG for the presence of effusion and bursitis

\begin{tabular}{|l|l|l|l|}
\hline & Bursitis & \multicolumn{1}{|c|}{$\begin{array}{c}\text { Biceps tendon } \\
\text { effusion }\end{array}$} & \multicolumn{1}{|c|}{$\begin{array}{c}\text { Glenohumeral joint } \\
\text { effusion }\end{array}$} \\
\hline $\begin{array}{l}\text { Diagnostic } \\
\text { accuracy }\end{array}$ & 93 & 92 & 83 \\
\hline Sensitivity & 73.1 & 37.5 & 26.1 \\
\hline Specificity & 100 & 100 & 100 \\
\hline PPV & 100 & 100 & 100 \\
\hline NPV & 26.9 & 92 & 81.9 \\
\hline Kappa (sig) & $\begin{array}{l}0.80 \\
(0.001)\end{array}$ & $0.456(0.001)$ & $0.352(0.001)$ \\
\hline
\end{tabular}

Based on table 8.a, the diagnostic accuracy of USG was calculated individually for the presence of effusions and bursitis. Overall, the diagnostic accuracy of USG was maximum for the identification of subacromial bursitis (93\%), followed by biceps tendon effusion and glenohumeral joint effusion i.e., $92 \%$ and $83 \%$ respectively.

Sensitivity, specificity, PPV, and NPV of USG for subacromial bursitis were $73.1 \%, 100 \%, 100 \%$, and $26.9 \%$ respectively. However, the sensitivity of USG for identification of biceps tendon sheath effusion was $37.5 \%$. 
Kappa statistics revealed a good and minimal level of agreement for identification of subacromial bursitis (0.80) and a minimal level of agreement for glenohumeral joint and biceps tendon sheath effusions ( 0.35 and 0.45 respectively).

Table-9: ROC curve for muscular- tendinous injuries of the rotator cuff on USG.

\begin{tabular}{|l|l|l|l|l|l|}
\hline \multicolumn{1}{|c|}{ Rotator cuff } & \multicolumn{1}{c|}{ AUC } & \multicolumn{1}{c|}{ SE } & \multicolumn{1}{c|}{ P value } & \multicolumn{2}{c|}{$95 \%$ CI } \\
\hline Supraspinatus & 0.862 & 0.041 & 0.001 & 0.781 & 0 \\
\hline Infraspinatus & 0.750 & 0.229 & 0.228 & 0.300 & 1.000 \\
\hline Subscapularis & 0.846 & 0.079 & 0.001 & 0.692 & 1.000 \\
\hline Biceps & 0.833 & 0.167 & 0.045 & 0.505 & 1.000 \\
\hline
\end{tabular}

In the present study, the area under the curve i.e., the diagnostic accuracy of USG was excellent (AUC>0.80; $p<0.05$ ) for diagnosis of supraspinatus (AUC 0.862; p 0.001), followed by subscapularis (AUC 0.846; p 0.001) and biceps tendon (AUC 0.833 ; $\mathrm{p}$ 0.045), whereas it was good for infraspinatus muscle tear (0.75; $p$ 0.22).

Table-10: ROC curve for diagnosis of effusions and bursitis.

\begin{tabular}{|l|c|c|l|c|c|}
\hline & AUC & SE & P value & \multicolumn{2}{|c|}{$95 \%$ CI } \\
\hline Bursitis & 0.865 & 0.053 & 0.001 & 0.761 & 0.970 \\
\hline Biceps tendon sheath effusion & 0.500 & 0.107 & 1.000 & 0.290 & 0.710 \\
\hline Glenohumeral joint effusion & 0.630 & 0.074 & 0.058 & 0.486 & 0.775 \\
\hline
\end{tabular}

In the present study, the area under the curve i.e. diagnostic accuracy of USG was excellent (AUC>0.80; $p<0.05$ ) for diagnosis of subacromial bursitis (AUC 0.865; p 0.001), followed by moderate for glenohumeral joint effusion (AUC 0.630; $p$ 0.058 ) and biceps tendon effusion (AUC 0.500).

\section{Discussion}

Rotator cuff injuries are the third leading cause of musculoskeletal disorder after low back and neck pain. The gold standard investigation modality for the identification of rotator cuff injury is MRI. The present study entitled "role of high-frequency USG in rotator cuff injury and its comparison with MRI" was thus conducted at the tertiary care center, to assess various rotator cuff tear with high-frequency USG and its comparison with MRI findings amongst patients of rotator cuff injuries reporting from Orthopedic department for investigation at Department of Radiodiagnosis.

\section{Socio-demographic variables Age}

Age is considered as a major risk factor for rotator cuff injuries i.e. such injuries are significantly associated with advancing age [15].
Rotator cuff injuries have been reported to be as high as $62 \%$ in elderly patients as compared to $9.7 \%$ in younger patients belonging less than 20 years [3]. Degeneration, microtrauma as well as hypervascularity of this region with advancing age has been linked to rotator cuff injury $[16,17]$.

In the present study, the majority of patients with rotator cuff injuries belonged to the age range of 21 to 30 years (34\%) with a mean age of $38.26 \pm 14.51$ years Only $8 \%$ and $7 \%$ of patients belonged to extremes of age i.e. $>60$ years and $<20$ years respectively.

The mean age of patients in a study by Bhatnagar $S$ et al 46 years and the majority of patients belonged to 41 to 50 years of age $(17 \%)$ [18].

However, the mean age of patients in a study by Chauhan NS et al was $51.9 \pm 13.3$ years which was much higher as compared to the present study [19].

\section{Gender}

Though the prevalence of rotator cuff injuries has been documented to be almost similar in males and females, few studies report a higher incidence in postmenopausal females [15].

However, in the present study, the majority of patients with rotator cuff injuries were males (74\%) whereas only $26 \%$ of patients were females.

These findings were supported by findings of Bhatnagar S et al, in which $72 \%$ of patients with rotator cuff injuries were males [18]. However, Chauhan NS et al documented male preponderance in a ratio of $2: 1$, which was similar to the present study i.e. 2.8:1 [19].

\section{USG and MRI for rotator cuff injuries}

In the present study, MRI and USG both were conducted on each patient, and the findings of USG were compared to that of MRI.

\section{Supraspinatus}

USG revealed supraspinatus muscle tear in 34\% of patients whereas MRI revealed supraspinatus muscle tear in $47 \%$ of patients in the present study. Supraspinatus is most commonly affected as it is located between the greater tuberosity and the acromion process leading to repeated friction during overhead abduction of the shoulder [20].

Overall, diagnostic accuracy, sensitivity, and specificity of USG for identification of supraspinatus tendon were documented to be $87 \%, 72.3 \%$, and 
$100 \%$ respectively. On applying kappa statistics, a moderate level of agreement was observed between the findings of USG and MRI for supraspinatus tendon tear. Overall, the diagnostic accuracy using ROC analysis for the diagnosis of supraspinatus tendon tear was found to be excellent (AUC-0.862) in the present study.

The findings of the present study were similar to the findings of Naganna HP et al in which authors documented sensitivity, specificity, PPV, NPV, and accuracy for supraspinatus tendon pathologies to be $75 \%, 66.7 \%, 90 \%, 40 \%$, and $73.7 \%$ respectively [21].

However, Thakker VD et al also documented supraspinatus injuries to be the most common among rotator cuff injuries (79\%). For partial tears, USG showed a sensitivity of $66.67 \%$, specificity of $92.5 \%$, PPV of $68.96 \%$, and NPV of $91.74 \%$. USG revealed a sensitivity of $100 \%$ for full-thickness tears [22].

\section{Infraspinatus}

MRI revealed infraspinatus injury in only $2 \%$ of cases, whereas USG revealed infraspinatus injury in only 1 case. The sensitivity, specificity, and PPV of USG for infraspinatus tendon tear was 50\%, 100\%, and $100 \%$ respectively. Kappa statistics revealed a moderate level of agreement (0.66) between USG and MRI findings for the diagnosis of infraspinatus tendon tear $(p<0.01)$. Overall ROC analysis revealed good diagnostic accuracy of USG for identification of infraspinatus tendon tear (AUC0.75; SE-0.229).

These findings were supported by findings of Thakker VD et al, in which thy documented sensitivity of USG to be $50 \%$ for infraspinatus tendon injury, and specificity and PPV of $100 \%$ similar to the present study. Kappa statistics revealed a moderate level of agreement (0.66) in the reference study similar to the present study [22]. However, Fischer CA et al documented diagnostic accuracy of $84.4 \%$ for the infraspinatus tendon [23].

\section{Subscapularis}

MRI showed subscapularis tendon involvement in $13 \%$ cases whereas USG revealed subscapularis injury in $9 \%$ cases only. Sensitivity and NPV of USG for diagnosis of the subscapularis tendon in the present study were $69.2 \%$ and $95.6 \%$ respectively whereas specificity and PPV were $100 \%$.
A moderate level of agreement was observed for subscapularis injuries between two diagnostic modalities, however, ROC analysis revealed excellent diagnostic accuracy (AUC-0.846). Naganna HP et al documented sensitivity, specificity, PPV, and NPV to be $66.7 \%, 95.8 \%, 80 \%$, and $92 \%$ respectively which was similar to the findings of the present study [21].

The findings of the present study were also supported by findings of Thakker VD et al in which sensitivity and specificity of USG were documented to be $75 \%$ and $93.48 \%$ respectively with a moderate level of agreement (0.60) [22].

\section{Biceps}

In the present study, biceps tear was documented in 3 cases, of which USG identified biceps tendon tear in two cases. Overall, diagnostic accuracy and negative predictive value of USG was $98.9 \%$. Sensitivity and specificity were $66.7 \%$ and $100 \%$ respectively. A strong level of agreement (0.80) was observed between USG and MRI for the identification of biceps injuries. ROC analysis showed an excellent diagnostic accuracy of USG for biceps tear ( $A \cup C>0.80$ ). The findings of the present study were similar to the findings of Ahmad $Z$ et al in which biceps tendinopathy was seen in two patients on USG, whereas MRI showed three cases of biceps tendinopathy [24].

Teefey SA et al documented that biceps tendon abnormalities frequently are associated with rotator cuff tear. [25].

Associated effusion and bursitis

\section{(A) Glenohuemral joint effusion}

The dynamics of the glenohumeral joint are affected by rotator cuff injuries [1]. The present study documented effusion at the glenohumeral area in 26 cases on MRI, of them 19 were identified on USG. The sensitivity, specificity, PPV, and NPV of USG were $73.1 \%, 100 \%, 100 \%$, and $26.9 \%$ respectively. Kappa statistics revealed a good level of agreement for the identification of glenohumeral joint effusion (0.80). The area under the curve was 0.865 which showed an excellent diagnostic accuracy of USG $(p<0.01)$.

These findings were similar to findings of Thakker VD et al in which the sensitivity and specificity of USG for subacromial sub deltoid fluid was documented to be $86.67 \%$ and $100 \%$ respectively [22]. 
The findings of the present study were also consistent with the findings of Hollister MS et al [26].

\section{(B) Biceps tendon sheath effusion}

Effusion along the biceps tendon is usually commonly associated with rotator cuff injuries. However, in the present study, it was observed in 8 cases by MRI whereas in none of the cases in USG. Thus USG had no sensitivity for the effusion of the biceps tendon. However, AUC i.e0.50 showed that the diagnostic test has no discriminatory ability for the presence of effusion of the biceps tendon.

Contrasting to the findings of the present study, Thakker VD et al documented $58.6 \%$ sensitivity for biceps tendon effusion [22]. The observed discrepancy between the present study and reference study could be due to the small sample size of the present study.

\section{(C) Bursitis}

MRI revealed bursitis in 23 cases in the present study, of them, USG showed bursitis in only 6 cases. For bursitis, USG was only $26.1 \%$ sensitive but $100 \%$ specific. Kappa statistics revealed the minimal level of agreement between USG and MRI for the identification of bursitis (0.35). The area under the curve was 0.630, which was less than the acceptability criteria.

Bhatnagar S et al observed bursitis in $73 \%$ of patients with rotator cuff injuries [18]. To the current knowledge, none of the studies observed the diagnostic accuracy for the identification of bursitis individually.

\section{Conclusion}

Based on the findings of the present study, it is concluded that rotator cuff injuries are commonly encountered conditions in routine practice, and males are commonly affected as compared to females.

The specificity and positive predictive value was $100 \%$ for all the muscular tears as well as associated joint effusion and bursitis, but sensitivity varies for individual tendon injury.

The sensitivity of USG was maximal for supraspinatus, followed by subscapularis and biceps tendon tears i.e. $72.3 \%, 69.2 \%$, and $66.7 \%$ respectively.
However, overall diagnostic accuracy was excellent for muscular injuries (AUC>0.80) except for infraspinatus tear, where diagnostic accuracy was in an acceptable range.

For associated glenohumeral joint effusion USG showed $73.1 \%$ sensitivity but the sensitivity was less than $25 \%$ for bursitis and biceps tendon effusion. For glenohumeral joint effusion, USG showed excellent diagnostic accuracy but it was none to minimal for biceps sheath effusion and bursitis.

\section{What does the study add to the existing knowledge?}

Though MRI is the gold standard technique for the identification of rotator cuff injuries, USG can be used alternatively as it is a non-invasive, rapid, and cost-effective diagnostic method. Overall, the diagnostic yield of USG for identification of individual muscular tears as well as glenohumeral joint effusion was observed to be good. Thus, it is recommended that all the patients presenting with shoulder pain must be screened for rotator cuff injuries using USG before subjecting them to MRI.

\section{Author's contribution}

Dr. Poornima Maravi: Concept and manuscript preparation

Dr. Ajay Khadiya: Study design

Dr. Lovely Kaushal: Statistical analysis

Dr. Swati Goyal: Manuscript preparation

Dr. Pinki Patil: Manuscript preparation

\section{Reference}

01. May T, Garmel GM. Rotator Cuff Injury, In Stat Pearls. Stat Pearls Publishing. 2019.

[Crossref]

02. Mitchell C, Adebajo A, Hay E, Carr A. Shoulder pain- diagnosis and management in primary care. BMJ. 2005;331(7525)1124-1128.

doi: $\quad 10.1136 / \mathrm{bmj} .331 .7525 .1124 \quad$ [Crossref]

03. Codding JL, Keener JD. Natural History of Degenerative Rotator Cuff Tears. Curr Rev Musculoskelet Med. 2018;11(1)77-85.

doi: $\quad 10.1007 / \mathrm{s} 12178-018-9461-8 \quad$ [Crossref] 
04. Inderhaug $\mathrm{E}$, Kalsvik M, Kollevold $\mathrm{KH}$, Hegna J, Solheim E. Long-term results after surgical treatment of subacromial pain syndrome with or without rotator cuff tear. J Orthop. $2018 ; 15(3) 757-760$.

doi: $10.1016 /$ j.jor.2018.03.004 [Crossref]

05. Nogueira-Barbosa MH, Volpon JB, Elias Jr J, Muccillo G. Diagnostic imaging of shoulder rotator cuff lesions. Acta Ortopédica Brasileira. 2002; 10(4)31-39.

doi: $10.1590 /$ S1413-78522002000400005 [Crossref]

06. Morag Y, Jon A Jacobson, Bruce Miller, Michel De Maeseneer, Gandikota Girish, David Jamadar. MR Imaging of rotator cuff injury- What the clinician needs to know. Radiograph. 2006;26(5)1045-1065.

[Crossref]

07. Morag $Y$, Jacobson JA, Miller B, De Maeseneer M, Girish G, Jamadar D. MR imaging of rotator cuff injury: what the clinician needs to know. Radiographics. 2006;26(4)1045-1065.

doi: $10.1148 / \mathrm{rg} .264055087$ [Crossref]

08. Dean Deyle G. The role of MRI in musculoskeletal practice- a clinical perspective. J Man Manip Ther. 2011;19(3)152-161.

doi: $10.1179 / 2042618611$ Y.0000000009 [Crossref]

09. de Jesus JO, Parker L, Frangos AJ, Nazarian LN. Accuracy of MRI, MR arthrography, and ultrasound in the diagnosis of rotator cuff tearsa meta-analysis. AJR Am J Roentgenol. 2009; 192(6)1701-1707.

doi: $10.2214 /$ AJR.08.1241 [Crossref]

10. Friedman RL, Hidalgo HJ, Gilmer PW, Mallon WJ. Ultrasonography of the rotator cuff- Analysis of results in a community setting. J Shoulder Elbow Surg. 1993;2(1)22-26.

doi: $10.1016 / S 1058-2746(09) 80133-X \quad$ [Crossref]

11. Sipola P, Niemitukia L, Kroger H, Hofling I, Vaatainen $U$. Detection and quantification of rotator cuff tears with ultrasonography and magnetic resonance imaging- a prospective study in 77 consecutive patients with a surgical reference. Ultrasound Med Biol. 2010;36(12)1981-1989.

doi: 10.1016/j.ultrasmedbio.2010.09.001 [Crossref]
12. Teefey SA, Rubin DA, Middleton WD, Hildebolt $\mathrm{CF}$, Leibold RA, Yamaguchi K. Detection and quantification of rotator cuff tears- comparison of ultrasonographic, magnetic resonance imaging, and arthroscopic findings in seventyone consecutive cases. J Bone Joint Surg Am. $2004 ; 86(4) 708-716$.

[Crossref]

13. Smith TO, Back T, Toms AP, Hing CB. Diagnostic accuracy of ultrasound for rotator cuff tears in adults- a systematic review and meta-analysis. Clin Radiol. 2011;66(11)1036-1048. doi: 10.1016/j.crad.2011.05.007 [Crossref]

14. Teefey SA, Middleton WD, Payne WT, Yamaguchi $\mathrm{K}$. Detection and measurement of rotator cuff tears with sonography- analysis of diagnostic errors. AJR Am J Roentgenol. 2005;184(6)17681773.

doi: $\quad 10.2214 /$ ajr.184.6.01841768 [Crossref]

15. Sambandam SN, Khanna V, Gul A, Mounasamy V. Rotator cuff tears- An evidence based approach. World J Orthop. 2015;6(11)902-918. doi: $10.5312 /$ wjo.v6.i11.902 [Crossref]

16. Yadav H, Nho S, Romeo A, MacGillivray JD. Rotator cuff tears- pathology and repair. Knee Surg Sports Traumatol Arthrosc. 2009;17(4)409-421.

doi: $\quad 10.1007 / \mathrm{s} 00167-008-0686-8 \quad$ [Crossref]

17. Rudzki JR, Adler RS, Warren RF, Kadrmas WR, Verma $N$, Pearle $A D$, et al. Contrast-enhanced ultrasound characterization of the vascularity of the rotator cuff tendon, age- and activityrelated changes in the intact asymptomatic rotator cuff. J Shoulder Elbow Surg. 2008;17(1)96S-100S.

doi: 10.1016/j.jse.2007.07.004 [Crossref]

18. Bhatnagar $S$, Kuber $R$, Shah D. The role of ultrasound and magnetic resonance imaging in the evaluation of musculotendinous pathologies of the shoulder joint. West Afr J Radiol. 2014;21(2)68-74.

doi: $10.4103 / 1115-1474.134611$ [Crossref] 
19. Chauhan NS, Ahluwalia A, Sharma YP, Thakur L. A prospective comparative study of highresolution ultrasound and MRI in the diagnosis of rotator cuff tears in a tertiary hospital of North India. Polish J Radiol. 2016;81;491.

doi: $10.12659 /$ PJR.897830 [Crossref]

20. Vlychou M, Dailiana Z, Fotiadou A, Papanagiotou M, Fezoulidis IV, Malizos K. Symptomatic partial rotator cuff tears- diagnostic performance of ultrasound and Magnetic resonance imaging with surgical correlation. Acta Radiol. 2009;50(1)101-105.

doi: $10.1080 / 02841850802600764$ [Crossref]

21. Naganna HP, Rangaswamy SM, Jaganathan NC, Lingaiah RK, Nagarajegowda PH. Study of Rotator Cuff Disorders by Ultrasound with Magnetic Resonance Imaging Correlation. Int J Contemp Med Surg Radiol. 2018;3(1)70-75.

[Crossref]

22. Thakker VD, Bhuyan D, Arora M, Bora MI. Rotator Cuff Injuries- Is Ultrasound Enough? A Correlation with MRI. Int Anat Radiol Surg. 2017;6(3)RO01-RO07.

doi: $10.7860 /$ IJARS/2017/28116:2279 [Crossref]
23. Fischer CA, Weber MA, Neubecker C, Bruckner T, Tanner $M$, Zeifang $F$, et al. Ultrasound vs MRI in the assessment of rotator cuff structure prior to shoulder arthroplasty. J Orthop. 2015;12(1)2330.

doi: $10.1016 /$ j.jor.2015.01.003 [Crossref]

24. Ahmad Z, Ilyas M, Wani GM, Choh NA, Gojwari TA, Ahmad Kazime MJ. Evaluation of rotator cuff tendinopathies and tears with high-resolution ultrasonography and magnetic resonance imaging correlation. Arch Trauma Res. 2018;7(1)15-23.

doi: 10.4103/atr.atr_20_17 [Crossref]

25. Teefey SA, Hasan SA, Middleton WD, Patel $M$, Wright RW, Yamaguchi K, et al. Ultrasonography of the rotator cuff- $A$ comparison of ultrasonographic and arthroscopic findings in one hundred consecutive cases. J Bone Joint Surg Am. 2000;82(4)498-504.

[Crossref]

26. Hollister MS, Mack LA, Patten RM, Winter 3rd TC, Matsen 3rd FA, Veith RR. Association of sonographically detected subacromial/ subdeltoid bursal effusion and intraarticular fluid with rotator cuff tear. Am J Roentgenol. $1995 ; 165(3) 605-608$.

doi: 10.2214/ajr.165.3.7645478 [Crossref] 